\title{
Voltage Security Evaluation Based on Perturbation Method
}

\author{
A. A. Gharaveisi, M. Rashidinejad, \\ Electrical Engineering Department, Shahid Bahonar University of Kerman, Kerman, Iran \\ and \\ A. Mousavi \\ Electronic and Computer Engineering Division, School of Engineering and Design, Brunel \\ University, United Kingdom
}

Abstract - This paper proposes a new algorithm for estimating voltage security margin. The algorithm is based on the perturbation method and has significant computational efficiency. The proposed algorithm can be used for on-line voltage security evaluation. It has been validated using IEEE-14, IEEE-30 and IEEE-57 bus systems. Results from the tests show higher efficiency and smaller error margins compared to Continuation Power Flow (CPF) method.

Voltage Collapse is a serious threat to the security of stressed power systems; therefore, voltage security (VS) has become a major challenge for management of power systems. The motivation for this research is a direct consequence of the deregulation of electricity industries and markets worldwide

Index Terms - Voltage security, voltage stability, P-V curve, nose curve, saddle-node bifurcation, perturbation parameter

\section{INTRODUCTION}

In order to secure loading margins one needs to take notice of the voltage instability phenomenon (VIP). Power system stabilizers (PSS) are widely used close to the rotor angle stability boundaries to secure the performance of stressed power systems [1]. The rotor-angle and voltage stability can be defined as a subset of the stability space of the power systems [2]. Moreover, voltage stability can be described as a synchronous generator supplying a static load via a line with $X_{L}$. In the event of a gradual load increase, the operating point of the system changes accordingly. Any partial increase of the load reaching the boundary of voltage stability (BoVS) point, also referred to as the saddlenode bifurcation (SNB) point, will significantly alter system characteristics. The Saddle Node Bifurcation (SNB) is by nature a nonlinear phenomenon and does not occur in a linear model. However, SNB can be as simple as a quadratic equation. Suppose the quadratic equation has two real roots (equilibrium solutions), as the parameters of a quadratic equation gradually change, the two real roots move and it is possible for the real roots to coalesce and disappear. The bifurcation occurs when a double root that separates the two incidents of two real roots from the instance has no real root (i.e. critical instances).

For example, consider the quadratic equation $-x^{2}-p=0, x$ represents the system state and the $p$ represents a system parameter. When $p$ is negative, then there are two equilibrium solutions $x_{0}=\sqrt{-p}$ and $x_{1}=-\sqrt{-p}$. If $p$ 
increases to zero, then both equilibria are at the double root $\mathrm{x}=0$. If $p$ increases further and becomes positive, there are no equilibrium solutions. The saddle node bifurcation occurs at $p=0$, and that is when the critical instance separates the case of two solutions from no real solutions. At the SNB point, the Jacobian matrix of power flow equations becomes singular with the eigenvalue of zero [3]. The phenomenon of voltage instability has been observed in large power systems. For example, the voltage collapse in west of France in 1987 due to the outage of 9000MW generation [4]; or the Tokyo incident in 1987 due to an extraordinary load growth rate of 400 MW per minute at noon time in a hot day [5]; or of the incident that took place at the Northern California network in 1983, where it resulted into a 2 minute blackout due to the outage of HVDC lines [6].

In order to determine voltage stability margin or the SNB point [7], two sets of methods have been proposed, the direct [8], [9] and the indirect methods [10], [11]. In the direct method, voltage security margin is derived from an optimization problem. In the indirect method power flow equations are continuously solved with respect to increases in load. The solution is based on reaching the power system voltage stability margin. For example, continuation power flow (CPF) is known as an indirect method.

Previous literature dealt with voltage collapse detection by using localised measurements [12-16]. For example, Verbic et al $(2003,2004)$ deploy phasors measured at the relaying point to compute the value of the apparent power difference criterion (SDC) [12], [13]. When the SDC becomes less than 0.2, the relay initiates a mitigation procedure. The method proposed by $\mathrm{Vu}$ et al (1999) is based on a comparison between Thevenin equivalent from the load bus and the apparent impedance of the load. The assessment of the distance to voltage instability is based on the fact that these two impedances are equal at the point of voltage collapse [14]. To accurately estimate the Thevenin equivalent, it is necessary to acquire two different load measurements at different times. This approach is the main disadvantage of this method. It seems that these methods fall short of providing the benefits of offering a measure of the distance from voltage collapse in terms of MW/MVA/Mvar. For example, a minimum SDC of 0.2 on lines carrying 2 MVA and 200 MVA results in largely varying values [12],[13]. Using localised measurements it is necessary to produce a method that helps to quantify the distance of the current operating point to voltage collapse in terms of real or estimated power increase.

Balamourougan et al (2004) propose a voltage collapse indicator [15]. Using this technique the system becomes increasingly stressed and the line losses start to grow rapidly near the voltage collapse point. At the collapse point, the loss-increasing ratios $d P_{\text {LOSS }} / d P, d P_{\text {LOSS }} / d Q, d Q_{L O S S} / d P$, and $d Q_{L O S S} / d Q$ tend towards infinity. This fact provides the theoretical background for the power-loss-sensitivity method [16]. It is proven that that the voltagecollapse condition using the power-loss-sensitivity method is identical to that of the Jacobian method.

This paper proposes a new method for evaluation of power system voltage security using perturbation technique. The proposed algorithm maintains the flexibility to determine the distance of the operating point with the voltage stability margin that support high convergence speed. A comparison with the CPF method [11] was made and validated through IEEE-14, 30 and 57 bus power systems. 


\section{Voltage STABILITY ASSESSMENT}

The possibility of voltage instability encourages the continuous real time monitoring and evaluation of voltage stability in power systems. Voltage stability phenomena can be evaluated using static and dynamic methods. The static voltage stability method adopts non-linear algebraic equations. The dynamic voltage stability method utilises the combination of non-linear differential and algebraic equations. Due to the importance of voltage stability in power systems, the energy management systems deploy voltage stability assessment (VSA) procedures [7]. The VSA process consists of five steps (Figure 1). These steps are:

Step1: Evaluate the voltage stability at current operating point. Sensitivity analysis is conducted on the eigenvalues of Jacobian Matrix. The system will reside in the voltage stability boundary provided that one of the values equal to zero.

Step 2: Select the contingency critical contingencies will be selected with respect to the current operating point which in turn is inferred from the VSA information.

Step 3: Rank and sort the contingencies based on their severity.

Step 4: Evaluate contingencies using the ranked contingencies from Step 3.

Step 5: Apply corrective/preventive strategy based on the optimal reactive power flow after contingency. Here, preventive strategy can be described as load shedding before any damage could occur.

\section{Figure 1: VSA procedure.}

\section{MATHEMATiCAL ModeLling}

In its general form power flow equations can be described as:

$$
F(\delta, V)=0
$$

Equation (1) includes $2\left(n_{1}+n_{2}\right)$ variables where $n_{1}$ is the number of PV buses and $n_{2}$ is the number of PQ buses, and $\delta$ and $\mathrm{V}$ are, respectively, the angle and magnitude of bus voltages. In voltage stability studies, power flow equations should be generalised [2]. To establish a generalised form of power flow equations, $\lambda$ is introduced as a parameter representing load variations:

$$
F(\delta, V, \lambda)=0 \quad ; \quad \lambda_{\mathrm{O}} \leq \lambda \leq \lambda_{\text {critical }}
$$

Equation (2) includes $2\left(\mathrm{n}_{1}+\mathrm{n}_{2}\right)$ equations and $2\left(\mathrm{n}_{1}+\mathrm{n}_{2}\right)+1$ variables, $\lambda=0$ represents the base case, and $\lambda=\lambda_{\text {critical }}$ indicates a critical load or the SNB point conditions. A generalised power flow equation for the $i^{\text {th }}$ bus can be 
formulated by combining the following expressions with respect to a rectangular form of power flow equations associated with $\lambda$ :

$$
\begin{aligned}
& P_{G i}-P_{D i}-P_{T i}=0 \\
& Q_{G i}-Q_{D i}-Q_{T i}=0
\end{aligned}
$$

where:

$$
\begin{aligned}
P_{T i}= & \sum_{k} G_{i k}\left(e_{i} e_{k}+f_{i} f_{k}\right)+ \\
& \sum_{k} B_{i k}\left(e_{k} f_{i}-e_{i} f_{k}\right) \\
Q_{T i}= & \sum_{k} G_{i k}\left(e_{k} f_{i}-e_{i} f_{k}\right)- \\
& \sum_{k} B_{i k}\left(e_{i} e_{k}+f_{i} f_{k}\right) \\
P_{D i}= & P_{D i \mathrm{O}}+\lambda\left(K_{D i} S_{\Delta b a s e} \cos \theta_{i}\right) \\
Q_{D i}= & Q_{D i \mathrm{O}}+\lambda\left(K_{D i} S_{\Delta b a s e} \sin \theta_{i}\right) \\
P_{G i}= & P_{G i \mathrm{O}}\left(1+\lambda K_{G i}\right)
\end{aligned}
$$

And:

$\mathrm{K}_{\mathrm{Gi}}$ : a factor indicating variations in generated power at $\mathrm{i}$-th bus

$\mathrm{P}_{\mathrm{Gi} 0}$ : real power generated at $\mathrm{i}$-th bus in base case

$\mathrm{Q}_{\text {Di0 }}$ : imaginary power load at $\mathrm{i}$-th bus in base case

$\mathrm{P}_{\mathrm{Di0}}$ : real power load at $\mathrm{i}$-th bus in base case

$\mathrm{K}_{\mathrm{Di}}$ : a factor indicating variations in load at $\mathrm{i}$-th bus

$\theta_{\mathrm{i}}$ : angle of power factor indicating variations in load at $\mathrm{i}$-th bus

$\mathrm{V}_{\mathrm{i}}$ : voltage at i-th bus

$\mathrm{S}_{\Delta \text { base }}$ : base apparent power due to $\lambda$

$y_{i k}$ : $(i, k)$-th element of $y_{\text {bus }}$ matrix

$\mathrm{G}_{\mathrm{ik}}=$ real part $\left(\mathrm{y}_{\mathrm{ik}}\right)$

$\mathrm{B}_{\mathrm{ik}}=$ imaginary part $\left(\mathrm{y}_{\mathrm{ik}}\right)$

$\mathrm{e}_{\mathrm{i}}=\operatorname{real} \operatorname{part}\left(\mathrm{V}_{\mathrm{i}}\right)$

$\mathrm{f}_{\mathrm{i}}=$ imaginary part $\left(\mathrm{V}_{\mathrm{i}}\right)$

\section{CONTINUATION POWER Flow}

The first step to evaluate the static voltage stability of a power system is to solve the power flow equations. The power flow equations adjacent to the SNB point diverge. This is due to the singularity of the Jacobian matrix at the SNB point. CPF method was proposed instead of the conventional power flow techniques to solve this problem.

The following section briefly discusses the generalised form of power flow equations using CPF method. 


\section{A. Continuation Load Flow Algorithm}

A locally parameterised continuation (LPC) technique was proposed by Rheinbolds (1986) [17]. In order to evaluate stability margin, CPF utilises LPC to solve generalised power flow equations. This can be achieved through generation of continuous solutions in the form of $\left(\mathrm{V}_{1}, \delta_{1}, \lambda_{1}\right),\left(\mathrm{V}_{2}, \delta_{2}, \lambda_{2}\right), \ldots$. In addition to the base case solution $\left(\left(\mathrm{V}_{0}, \delta_{0}, \lambda_{0}\right),\left(\lambda_{0}<\lambda_{1}<\lambda_{2}\right)\right)$ in conventional power flow, Figure 2 provides a schematic view of CPF predictive (1) and parameterised and corrective (2) stages. Note that $\mathrm{V}$ represents voltage and $\lambda$ represents load variation.

\section{Figure 2: Continuation Power Flow Schematic: Predictive (1), Parameterised and Corrective (2) stages}

\section{B. Predictive Stage}

At this stage, an approximate solution is derived from the generalised power flow equations starting from the base case and in the direction of tangent vector to the $\mathrm{V}-\lambda$ curve. Therefore, the first task is to calculate the tangential vector, which can be derived by differentiating both sides of the equation (2):

$$
d F=F_{\delta} d \delta+F_{V} d V+F_{\lambda} d \lambda
$$

It yields:

$$
d F=\left[F_{\delta}, F_{V}, F_{\lambda}\right] t
$$

with

$$
t=[d \delta, d V, d \lambda]^{T}
$$

Where: $\left[F_{\delta} F_{V}, F_{\lambda}\right]$ is a $2\left(\mathrm{n}_{1}+\mathrm{n}_{2}\right) \times 2\left(\mathrm{n}_{1}+\mathrm{n}_{2}\right)+1$ matrix and $t$ is a $\left(2\left(\mathrm{n}_{1}+\mathrm{n}_{2}\right)+1\right) \times 1$ vector. The tangential vector $t$ yields:

$$
\left[F_{\delta}, F_{V}, F_{\lambda}\right] t=0
$$

Thereafter, solutions for the predictive stage can be estimated by solving (8):

$$
\begin{aligned}
& \delta^{*}=\delta+\sigma d \delta \\
& V^{*}=V+\sigma d V
\end{aligned}
$$




$$
\lambda^{*}=\lambda+\sigma d \lambda
$$

In Equations 9(a-c), “*” is used for the predictive stage solutions and $\sigma$ is the step size. The step size is selected in such a way that the predictive stage solutions can be located within the convergence radius of the corrective stage [18].

\section{Parameterisation and the Corrective Stage}

The calculated values from the predictive stage that do not reach the $\mathrm{V}-\lambda$ curve need to be corrected. The corrective action is to transfer the values on to the $\mathrm{V}-\lambda$ curve (e.g. $\left.\mathrm{V}_{1}, \delta_{1}, \lambda_{1}\right)$. At this stage the number of variables is more than the number of equations by one. The variable vector for this stage can be presented as:

$$
X=[\delta, V, \lambda]^{T}
$$

Where $X$ is a $\left(\left(2 \mathrm{n}_{1}+\mathrm{n}_{2}\right)+1\right) \times 1$ vector. The solutions for the corrective stage can be deducted from ascertaining one variable from vector $X$, (e.g., $\left.X_{k}=\mu\right)$ and then solving the following equations using Newton-Raphson method:

$$
\begin{aligned}
& F(X)=0 \\
& X_{k}-\mu=0
\end{aligned}
$$

At each stage of the corrector in LPC technique, only one variable of $X$ can be certain, which is defined as the continuation parameter. This parameter corresponds to the maximum possible value in vector $t$. Therefore, continuation parameter will be the same variable as in the predicting stage and can be determined by:

$$
\mu=\left\{X_{k}:\left|t_{k}\right|=\operatorname{MAX}, 2 \leq k \leq 2 n_{1}+n_{2}+1\right\}(12)
$$

The continuation parameter " $\mu$ " in the initial step is $\lambda$, but for the next steps it can be chosen as a voltage magnitude or a voltage angle. By approaching the voltage stability margin $(\Delta \lambda=0), \lambda$ reaches its critical value. Beyond the critical point, $\lambda$ tends to decrease and variations of $\lambda$ become negative. $\Delta \lambda$ can therefore be taken as an index to discriminate voltage stability margin.

\section{Perturbation Method}

In order to address the voltage security problem it is necessary to solve the generalised power flow equations by increasing $\lambda$ from the base case load parameter $\left(\lambda_{0}\right)$ to $\lambda_{\text {cr }}$ (load parameter critical value). The value of $\left(\lambda_{\text {cr }}-\lambda_{0}\right)$ is considered as an index that represents marginal voltage security. The generalised power flow model consists of 
$2\left(n_{1}+n_{2}\right)$ equations and $2\left(n_{1}+n_{2}\right)+1$ variables, in which the number of equations are less than the number of variables by 1 .

In the proposed model discussed in this paper one of the variables acts as the perturbation parameter. This is within the context of perturbation technique [19]. The perturbed algebraic equation (13) with perturbation parameter $\varepsilon$ which $\varepsilon<1$ is represented:

$$
f(x, \varepsilon)=0
$$

Let perturbation parameter be zero, then (13) can be rewritten as:

$$
f(x)=0
$$

If the solution for equation (14) equals to $x_{0}$, then the solution for equation (13) with respect to $\varepsilon$ can be:

$$
x=x_{0}+\sum_{q=1}^{\infty} x_{q} \varepsilon^{q}
$$

By combining (13) and (15), $x_{q}$ is calculated. Since $\varepsilon$ is much lesser than one, $x$ can be written as:

$$
x \approx x_{0}+\sum_{q=1}^{p} x_{q} \varepsilon^{q}
$$

All terms with powers greater than $p$ can be considered as negligible with the error of orders $\varepsilon^{p+1}$.

\section{A. The Results}

\section{THEOREM 1:}

Consider a rectangular form of generalised power flow equations, provided that $\varepsilon_{\lambda}=\Delta \lambda$ is the perturbation parameter, then the real part and the imaginary part of the voltage is derived from the following equations:

$$
\begin{aligned}
& e_{i}=e_{i, 0}+e_{i, 1} \varepsilon_{\lambda}{ }^{2}+\cdots+e_{i, p_{1}} \varepsilon_{\lambda} p_{1} \\
& f_{i}=f_{i, 0}+f_{i, 1} \varepsilon_{\lambda}{ }^{2}+\cdots+f_{i, p_{1}} \varepsilon_{\lambda}^{p_{1}} \\
& i=2,3, \cdots, n
\end{aligned}
$$

Where $e_{i, 0}$ and $f_{i, 0}$ are real and imaginary part of the $i^{\text {th }}$ voltage in the base case, and $e_{i, 1}$ to $e_{i, p 1}$ and $f_{i, 1}$ to $f_{i, p 1}$ can be derived as follows: 


$$
\begin{aligned}
& {\left[\begin{array}{l}
E_{q} \\
F_{q}
\end{array}\right]=J_{0}{ }^{-1}\left[\begin{array}{l}
\alpha_{q} \\
\beta_{q}
\end{array}\right]} \\
& q=1,2,3, \ldots, p_{1}
\end{aligned}
$$

Where

$$
\begin{aligned}
& J_{0}=\left[\begin{array}{ll}
A & B \\
C & D
\end{array}\right] \\
& E_{q}=\left[e_{2, q}, \mathrm{~L}, e_{n, q}\right]^{T} \\
& F_{q}=\left[f_{2, q}, \mathrm{~L}, f_{n, q}\right]^{T} \\
& \alpha_{q}=\left[\alpha_{2, q}, \mathrm{~L}, \alpha_{n, q}\right]^{T} \\
& \beta_{q}=\left[\beta_{2, q}, \mathrm{~L}, \beta_{n, q}\right]^{T}
\end{aligned}
$$

Proof: The proof is achieved by substituting variables described in (17) and (18) into the rectangular form of generalised power flow equations (3) and (4) [21]. Summary of the proof is given in the Appendix.

\section{THEOREM 2:}

Provided that the perturbation parameter is considered to be a rectangular form of generalised power flow and as the variation of real part of the voltage at the critical bus is defined as $\mathrm{e}_{\mathrm{indx}}=\mathrm{e}^{*}-\varepsilon_{\mathrm{eindx}}$, then the real and imaginary parts of bus voltages, and load parameter " $\lambda$ " can be derived as:

$$
\begin{aligned}
& e_{i}=e_{i, 0}+e_{i, 1} \varepsilon_{e}+e_{i, 2} \varepsilon_{e}{ }^{2}+\cdots+e_{i, p_{2}} \varepsilon_{e} p_{2} \\
& i \neq i n d x, i=2,3, \ldots, n \\
& f_{i}=f_{i, 0}+f_{i, 1} \varepsilon_{e}+f_{i, 2} \varepsilon_{e}{ }^{2}+\cdots+f_{i, p_{2}} \varepsilon_{e} p_{2} \\
& i=2,3, \ldots, n \\
& \lambda=\lambda_{0}+\lambda_{1} \varepsilon_{e}+\lambda_{2} \varepsilon_{e}{ }^{2}+\cdots+\lambda_{p_{2}} \varepsilon_{e} p_{2}
\end{aligned}
$$

Where $\varepsilon_{\mathrm{e}}=\varepsilon_{\text {eindx }}, \lambda_{0}$ is the base load, $\mathrm{e}_{\mathrm{i}, 0}$ and $\mathrm{f}_{\mathrm{i}, 0}$ are real and imaginary part of the $\mathrm{i}^{\text {th }}$ bus voltage in the base case, and $\mathrm{e}_{\mathrm{i}, 1}$ to $\mathrm{e}_{\mathrm{i}, \mathrm{p} 2}$ and $\mathrm{f}_{\mathrm{i}, 1}$ to $\mathrm{f}_{\mathrm{i}, \mathrm{p} 2}$ and $\lambda_{1}$ to $\lambda_{\mathrm{p} 2}$ are derived from: 


$$
\begin{aligned}
& {\left[\begin{array}{c}
E_{q}^{\prime} \\
F_{q} \\
\lambda_{q}
\end{array}\right]=\left(J^{\prime} 0\right)^{-1}\left[\begin{array}{c}
\alpha^{\prime} q \\
\beta_{q}^{\prime} \\
\gamma_{q}
\end{array}\right]} \\
& q=1,2,3, \ldots, p_{2} \\
& J^{\prime} 0=\left[\begin{array}{ccc}
A^{\prime} & B^{\prime} & M \\
C^{\prime} & D^{\prime} & N \\
H & J & L
\end{array}\right]
\end{aligned}
$$

Where $E_{k}^{\prime}$ is the vector obtained by eliminating $e_{i n d x}$ variable from $E_{k}$. Similarly, by discarding a row and/or a column corresponding to the index in matrices $\mathrm{A}, \mathrm{B}, \mathrm{C}$ and $\mathrm{D}$ the respective results will be matrices $\mathrm{A}^{\prime}$. B', $\mathrm{C}^{\prime}$, and $\mathrm{D}^{\prime}$.

Proof: The proof can be simply achieved by substituting variables described in (25) - (27), into the rectangular form of generalised power flow equations [21]. Summary of the proof is given in the Appendix.

\section{Figure 3: Proposed Method Flowchart}

\section{B. The Perturbation Algorithm}

Based on Theorem I the voltage stability of a power system can be calculated using the proposed algorithm. Calculations start from the base case by increasing the load as a perturbation parameter $\varepsilon_{\lambda}$. At voltage stability margin proximity, matrix $J_{0}$ is singular. Therefore, to accurately estimate the voltage stability margin, perturbation parameter should be changed from $\varepsilon_{\lambda}$ to $\varepsilon_{\text {eindx }}$. By considering the results of Theorem II, voltage stability margin can be calculated by subtracting the real part of voltage at the critical bus. The flowchart of the proposed method is shown in Fig. 3. Following the proposed algorithm two issues need to be clarified. The first issue is the definition of critical bus, and the second is to realise the condition that perturbation parameter change from $\varepsilon_{\lambda}$ to $\varepsilon_{\text {eindx }}$.

Any bus with the highest ratio of voltage drop with respect to load variations is recognized as a critical bus. Hence the critical bus is represented by:

$$
\begin{aligned}
& \text { ind } x=\left\{i:\left|\frac{\Delta V_{i}}{\Delta \lambda}\right|=M A X,\right. \\
& \left.2 \leq i \leq 2\left(n_{1}+n_{2}\right)+1\right\}
\end{aligned}
$$

In the proposed method, perturbation parameter is changed from $\varepsilon_{\lambda}$ to $\varepsilon_{\text {eindx }}$ according to the slope of the V- $\lambda$ curve 
$\left(\Delta \mathrm{v}_{\text {indx }} / \Delta \lambda\right)$. As it can be seen from Fig. $3, \mathrm{z}^{*}$ is the slope of $\mathrm{V}-\lambda$ curve, in which the perturbation parameter is changed from $\varepsilon_{\lambda}$ to $\varepsilon_{\text {eindx. }} Z_{\text {cr }}$ is the slope (infinity) of $V-\lambda$ curve where the highest value of the load parameter $\left(\lambda_{\mathrm{cr}}\right)$ resides.

\section{CASE STUdies}

The proposed method is applied to IEEE test systems (IEEE 14, 30 and 57 bus) [20]. Reactive power generation constraints for buses are used as voltage control factors in simulation process. Table I shows the results of two different simulations of an IEEE 14-bus system considering one per-unit increase in load with respect to the base case. Perturbation parameter $\left(\varepsilon_{\lambda}\right)$ is considered to be 0.25 for the first simulation and $\varepsilon_{\lambda}=0.1$ for the second simulation. The results of the simulations for three values of $\mathrm{p}_{1}$ (i.e., 5, 6 and 7) are available in Table I. The results of the CPF method for $\Delta \lambda=0.2$ are also given for comparison purposes.

\section{TABLE 1: BUS VOLTAGES OF IEEE-14 BUS FOR DUE TO 1 PER-UNIT INCREASE IN LOAD WITH RESPECT TO THE BASE LOAD PATTERN}

In order to compare the proposed method with the CPF method a simulation of 4 iterations for $\varepsilon_{\lambda}=0.25$, and 10 iterations for $\varepsilon_{\lambda}=0.1$ was conducted. The results show that using the CPF method the results are achieved after 4 iterations, where each iteration requires 4 to 8 matrix inversions. In contrast in the proposed method one matrix inversion is required to achieve results for each iteration.

\section{TABLE 2: A comparison between the computational time between the proposed method and that of CPF method}

The test reveals that the proposed method:

1. Is more efficient due to lesser computing overhead.

2. Has smaller error margin compared to the CPF $\operatorname{method}^{1}$ (Table I).

In addition, compared to the CPF method that depends on a predefined step size for the prediction stage, the proposed method does not require the convergence condition at the correction stage. The reason for this effectiveness is that the proposed algorithm requires only one-stage to solve the problem, where the only condition for convergence is the perturbation parameter to be less than one $(\varepsilon<1)$. This implies that for higher $\varepsilon$ higher powers of $\mathrm{p}_{1}$ is required. Results of an IEEE 4-bus at saddle-node-bifurcation point are presented in Table 2.

Three different simulations are conducted based on the proposed method, where perturbation parameter $\left(\varepsilon_{\lambda}\right)$ is

\footnotetext{
${ }^{1}$ By increasing $\mathrm{p}_{1}$ the relative error will decrease significantly.
} 
assumed to be 0.1 for the first stage. After 1 per-unit increase in load the perturbation parameter is lowered to 0.05. After the growing load up to 1.3 per-unit, perturbation parameter is changed from $\varepsilon_{\lambda}$ to $\varepsilon_{\mathrm{e} 14}$ and the new value of $\varepsilon_{\mathrm{e} 14}$ would be 0.05 . According to Table 3, the relative error percentage (REP) for three different simulations is calculated as follows:

$$
\begin{aligned}
& R E P \operatorname{Sim} 1=100 \times \frac{1.4997-1.5187}{1.5187}=-1.25 \% \\
& R E P \operatorname{Sim} 2=100 \times \frac{1.5141-1.5187}{1.5187}=-0.3 \% \\
& R E P \operatorname{Sim} 3=100 \times \frac{1.5181-1.5187}{1.5187}=-0.04 \% \approx 0
\end{aligned}
$$

The results show that the estimated error tends towards zero in Sim3. Consequently, through proper selection of perturbation parameter $\varepsilon_{\text {eindx }}$ it is possible to achieve more accurate solutions using the proposed method.

\section{TABLE 3: BUS VOLTAGES OF IEEE-14 BUS FOR DUE INCREASE IN LOAD AT SADDLE-SNB POINT RELATED TO THE BASE LOAD PATTERN}

Voltage security margin derived by the proposed method is compared with the CPF for three different IEEE test systems.

\section{TABLE 4: SNB POINT PROPERTY $\left(\lambda_{\mathrm{CR}}\right)$ IN IEEE-BUS STANDARDS}

The V- $\lambda$ curve inferred by the proposed method for critical bus and two voltage control buses in IEEE-57 bus, IEEE-30 bus and IEEE-14 bus systems are shown in Figures 4 to 9 . The 10 cardinal points of the lower part of V- $\lambda$ curve in IEEE-57 bus, IEEE-30 bus and IEEE-14 bus systems are indicated in Tables 5 to 7.

Figure 4: V- $\lambda$ Curve for critical Bus $\left(31^{\text {st }}\right)$ in network complying IEEE- 57 BUS system 
Figure 5: V- $\lambda$ Curve for critical Bus $\left(30^{\text {th }}\right)$ in network complying IEEE- 30 BUS system

Figure 6: V- $\lambda$ Curve for critical Bus $\left(14^{\text {th }}\right)$ in network complying IEEE- 14 BUS system

Figure 7: V- $\lambda$ Curve for Voltage Control Buses $\left(2^{\text {nd }}, 3^{\text {rd }}\right)$ of IEEE- 57 BUS System.

Figure 8: V- $\lambda$ Curve for Voltage Control Buses of IEEE- 30 BUS System.

Figure 9: V- $\lambda$ Curve for Voltage Control Buses of IEEE- 14 BUS System.

TABLE 5: TEN POINTS OF LOWER PART OF V- $\lambda$ CURVE IN IEEE- 57 BUS SYSTEM

(* SNB POINT)

\section{TABLE 6: TEN POINTS OF LOWER PART OF V- $\lambda$ CURVE IN IEEE- 30 BUS SYSTEM \\ (*SNB POINT)}

\section{TABLE 7: TEN POINTS OF LOWER PART OF V- $\lambda$ CURVE IN IEEE- 14 BUS SYSTEM (* SNB POINT)}

The Estimation of VSM for contingency state has been conducted for 5 buses for three IEEE 14, 30 and 57 test system results are listed in Table 8.

\section{TABLE 8: Estimation of VSM for Contingency state using the proposed method}

\section{CONCLUSION}

In this paper, a new method for evaluation of voltage stability phenomena in power systems and the determination of voltage stability boundaries is developed. It demonstrates that the proposed method has significant advantages to $\mathrm{CPF}$ method. This is achieved by proposing a single stage matrix inversion operation for every iteration, resulting into savings in computing overheads and more accurate results when compared to continuation power flow method. The proposed method can also be used to plot V- $\lambda$ curves. Similarly, using the proposed method the saddle-nodebifurcation point of the power system could accurately be determined. Provided the perturbation parameters are selected appropriately, the results can be obtained at higher computing speed. 


\section{REFERENCES}

[1] Mansour Y, W Xu, F Alvarado, C Rinzin, BC Hydro, "SVC Placement Using Critical Modes of Voltage Instability”, IEEE Transaction on Power Systems, vol.9, May 1994, pp. 757-763.

[2] Ajjarapu, V, Lee, B, "Voltage Stability \& Long-Term Stability Working Group, Iowa State Univ., Ames, IA", IEEE Transaction on Power Systems, Feb 1998, Volume: 13, Issue: 1, pp 115-125

[3] Galiana F.D., "Load Flow Feasibility and the Voltage Collapse Problem", Proceedings of the 23rd IEEE Conference on Decision and Control, Vol. 1, pp.485-487, December 1984.

[4] Taylor C.W., Power System Voltage Stability, Mc Graw-Hill Int. Editions 1994.

[5] Kuita A. and Sakurai T., “The Power System Failure on July 23, 1987 in Tokyo”, IEEE Proceeding. Dec. 1988, pp. 2093-2097.

[6] North American Electric Reliability Council, 1989 System Disturbances, July 1990.

[7] Ejbebe G.C. and et. al., "Methods for Contingency Screening and Ranking for Voltage Stability Analysis of Power Systems", IEEE Trans. On PWRS, Feb. 1995, pp. 350-356.

[8] Seydel R., From Equilibrium to Chaos, Elsever Science Publishing Co. Inc., 1988.

[9] Moore G. and Spence A. “The Calculation of Tuning Points of Nonlinear Equations”, SIAM J. Num. Analy. 17 (1980), pp. 567-576.

[10] Jubicek M. and Marek M., Computational Methods in Bifurcation Theory and Dissipative Structures, SpringerVerlag, 1983.

[11] Ajjarapu V. and Christy C., "The Continuation Power Flow: A Tool for Steady State Voltage Stability Analysis", IEEE Trans. on PWRS, Feb. 1992, pp. 416-423.

[12] G. Verbic and F. Gubina, "Fast voltage-collapse line-protection algorithm based on local phasors," in Proc. Inst. Elect. Eng., Gen. Transm. Distrib., Jul. 2003, vol. 150, no. 4, pp. 482-486.

[13] G. Verbic and F. Gubinar, “A new concept of voltage-collapse Protection based on local phasors," IEEE Trans. Power Del., vol. 19, no. 2, pp. 576-581, Apr. 2004.

[14] K. Vu, M.M. Begovic, D. Novosel, and M. M. Saha, "Use of local measurements to estimate voltage-stability margin,” IEEE Trans. Power Syst., vol. 14, no. 3, pp. 1029-1034, Aug. 1999.

[15] V. Balamourougan, T. S. Sidhu, and M. S. Sachdev, "Technique for online prediction of voltage collapse," in Proc. Inst. Elect. Eng., Gen., Transm. Distrib., Jul. 2004, vol. 151, no. 4, pp. 453-460.

[16] Y. H. Moon, H.-S. Ryu, and J.-G. Lee, "Uniqueness of static voltage stability analysis in power systems," in Proc. IEEE Power Eng. Soc. Summer Meeting, Vancouver, BC, Canada, 2001.

[17] Rheinbolds W.C., Numerical Analysis of Parameterized Nonlinear Equations, John Wiley \& Sons, New York, 1986.

[18] Rheinbolds W.C. and Vurkradt J.V., "A Locally Parameterized Continuation Process", ACM Trans. on Mathematica Software, June 1983.

[19] Nayfah A.H., Introduction to Perturbation Techniques, John Wiley \& Sons Int., 1981.

[20] Wallach Y., Calculation and Programs for Power System Networks, Prentice-Hall Int., Engle Wood, 1986. 
[21] A.A. Gharaveisi, A New Method For Evaluation of Bifurcation in Nonlinear Autonomous Systems, Ph.D. Thesis, Ferdowsi University of Mashhad, Iran, 2001.

\section{APPENDIX}

Theorem I:

The entries in $(20-(24)$ are given as follows:

$$
\begin{aligned}
& A_{i, i}=\sum_{j \neq 1}\left(G_{i j} e_{j, 0}-B_{i j} f_{j, 0}\right)+\left(G_{i i} e_{i, 0}+B_{i i} f_{i, 0}\right) \\
& +G_{i 1} e_{1} \\
& A_{i, j}=G_{i j} e_{i, 0}+B_{i j} f_{i, 0} \\
& B_{i, i}=\sum_{j \neq 1}\left(G_{i j} f_{j, 0}+B_{i j} e_{j, 0}\right)+\left(G_{i i} f_{i, 0}-B_{i i} e_{i, 0}\right) \\
& +B_{i 1} e_{1} \\
& B_{i, j}=G_{i j} f_{i, 0}-B_{i j} e_{i, 0} \\
& C_{i, i}=-\sum_{j \neq 1}\left(G_{i j} f_{j, 0}+B_{i j} e_{j, 0}\right)+\left(G_{i i} f_{i, 0}+B_{i i} e_{i, 0}\right) \\
& -B_{i 1} e_{1} \\
& C_{i, j}=G_{i j} f_{i, 0}-B_{i j} e_{i, 0} \\
& D_{i, i}=\sum_{j \neq 1}\left(G_{i j} e_{j, 0}-B_{i j} f_{j, 0}\right)-\left(G_{i i} e_{i, 0}+B_{i i} f_{i, 0}\right) \\
& +G_{i 1} e_{1} \\
& D_{i, j}=-G_{i j} e_{i, 0}-B_{i j} f_{i, 0} \\
& \alpha_{i, 1}=K_{G i}-K_{D i} \beta_{i, 1}=-K_{D i} T A N \theta_{i} \\
& \alpha_{i, q}=-\sum_{j \neq 1}\left\{G_{i j} \sum_{q=1}^{p-1}\left(e_{i, q} e_{j, p-q}+f_{i, q} f_{j, p-q}\right)\right. \\
& \left.+B_{i j} \sum_{q=1}^{p-1}\left(e_{j, q} f_{i, p-q}-e_{i, q} f_{j, p-q}\right)\right\} \\
& \beta_{i, q}=-\sum_{j \neq 1}\left\{G_{i j} \sum_{q=1}^{p-1}\left(e_{j, q} f_{i, p-q}-e_{i, q} f_{j, p-q}\right)\right. \\
& \left.-B_{i j} \sum_{q=1}^{p-1}\left(e_{i, q} e_{j, p-q}+f_{i, q} f_{j, p-q}\right)\right\} \\
&
\end{aligned}
$$

Theorem II:

The entries in (280 and (29) are given as follows:

$$
\begin{aligned}
& M_{i}=K_{D i}-K_{G i} \quad ; \quad i \neq i n d x \\
& N_{i}=K_{D i} \operatorname{TAN} \theta_{i} \\
& \boldsymbol{H}_{i}=\boldsymbol{G}_{\text {ind } x, i} \boldsymbol{e}_{\text {ind } x}+\boldsymbol{B}_{\text {ind } x, i} f_{\text {ind } x, 0} ; \quad i \neq \text { ind } x \\
& J_{i}=G_{\text {ind } x, i} f_{\text {indx }}-B_{\text {ind } x, i} e_{\text {ind } x, 0} ; \quad i \neq \text { ind } x \\
& \boldsymbol{I}_{\text {ind } x}=\sum_{j \neq 1}\left(\boldsymbol{G}_{\text {ind }, j} f_{j, \mathrm{O}}+\boldsymbol{B}_{\text {ind }, j, j} \boldsymbol{e}_{j, \mathrm{O}}\right) \\
& +\left(G_{\text {ind } x, \text { ind } x} f_{\text {ind } x, 0}-B_{\text {ind } x, \text { ind } x} e_{\text {ind } x}\right) \\
& L=K_{D, \text { ind } x}-K_{G, \text { ind } x}
\end{aligned}
$$

For $\mathrm{q}=1$, the values of $\alpha_{q}^{\prime}, \beta_{q}^{\prime}, \gamma_{q}$ are expressed by: 


$$
\begin{aligned}
& \alpha_{1, i}^{\prime}=G_{i, \text { ind } x} e_{i, 0}+B_{i, \text { ind } x} f_{i, 0} \quad ; \quad i \neq i n d x \\
& \beta_{1, i}^{\prime}=G_{i, \text { ind } x} f_{i, 0}-B_{i, \text { ind } x} e_{i, 0} \quad ; \quad i \neq i n d x \\
& \beta_{1, \text { ind } x}^{\prime}=-\sum_{j \neq 1}\left(G_{i n d x, j} f_{j, 0}+B_{i n d x, j} e_{j, 0}\right)+ \\
& \left(G_{i n d x, i n d x} f_{i n d x, 0}-B_{\text {ind } x, i n d x} e_{i n d x}\right)-B_{i n d x, 1} e_{1} \\
& \gamma_{1, i n d x}=\sum_{j \neq 1}\left(G_{i n d x, j} e_{j, 0}-B_{i n d x, j} f_{j, 0}\right)+ \\
& \left(G_{i n d x, i n d x} e_{i n d x}+B_{i n d x, i n d x} f_{i n d x}\right)+G_{i n d x, 1} e_{1}
\end{aligned}
$$

And for $\mathrm{q}>1(\mathrm{q}=2,3, \ldots, \mathrm{p})$ the values of $\alpha_{q}^{\prime}, \beta_{q}^{\prime}, \gamma_{q}$ are given through:

$$
\begin{aligned}
& \alpha_{i, q}^{\prime}=-\sum_{j \neq 1, i}\left\{G_{i j} \sum_{q=1}^{p-1}\left(e_{i, q} e_{j, p-q}+f_{i, q} f_{j, p-q}\right)\right. \\
& +B_{i j} \sum_{q=1}^{p-1}\left(e_{j, q} f_{i, p-q}-e_{i, q} f_{j, p-q}\right) \\
& \left.\quad-G_{i, \text { ind } x} \sum_{q=1}^{p-1}\left(f_{i n d x, q} f_{i, p-q}-e_{i, p-1}\right)\right\} \\
& +B_{i, \text { ind } x} \sum_{q=1}^{p-1}\left(f_{i, q} e_{i n d x, p-q}+f_{i, p-1}\right) \\
& \beta_{i, q}^{\prime}=-\sum_{j \neq 1, i}\left\{G_{i j} \sum_{q=1}^{p-1}\left(e_{j, q} f_{i, p-q}-e_{i, q} f_{j, p-q}\right)\right. \\
& -B_{i j} \sum_{q=1}^{p-1}\left(e_{i, q} e_{j, p-q}+f_{i, q} f_{j, p-q}\right) \\
& \left.\quad+G_{i, \text { ind } x} \sum_{q=1}^{p-1}\left(e_{i, q} f_{\text {ind } x, p-q}+f_{i, p-1}\right)\right\} \\
& +B_{i, \text { ind } x} \sum_{q=1}^{p-1}\left(f_{\text {ind } x, q} f_{i, p-q}-e_{i, p-1}\right) \\
& \gamma_{q}=-\sum_{j \neq 1, i}\left\{G_{i n d x, j} \sum_{q=1}^{p-1}\left(f_{i, q} f_{j, p-q}-e_{j, p-1}\right)\right. \\
& \left.+B_{\text {ind } x, j} \sum_{q=1}^{p-1}\left(e_{j, q} f_{\text {ind } x, p-q}+f_{j, p-1}\right)\right\} \\
& \quad-G_{\text {ind } x, \text { ind } x} \sum_{q=1}^{p-1} f_{\text {ind } x, q} f_{\text {ind } x, p-q}
\end{aligned}
$$

Finally, $\beta_{\text {ind }, q}^{\prime}$ can be calculated by:

$$
\begin{gathered}
\beta_{\text {ind } x, q}^{\prime}=-\sum_{j \neq 1, i}\left\{G_{\text {ind } x, j} \sum_{q=1}^{p-1}\left(e_{j, q} f_{\text {ind } x, p-q}+f_{j, p-1}\right)\right. \\
\left.-B_{\text {ind } x, j} \sum_{q=1}^{p-1}\left(f_{\text {ind } x, q} f_{j, p-q}-e_{j, p-1}\right)\right\} \\
+B_{\text {indx }, \text { ind } x} \sum_{q=1}^{p-1} f_{\text {ind }, q} f_{\text {ind } x, p-q}
\end{gathered}
$$


VSE List of Tables

Mousavi, A., Gharaveisi, A. and Rashidinejad M

TABLE 1: BUS VOLTAGES OF IEEE-14 BUS FOR DUE TO 1 PER-UNIT INCREASE IN LOAD WITH RESPECT TO THE BASE LOAD PATTERN

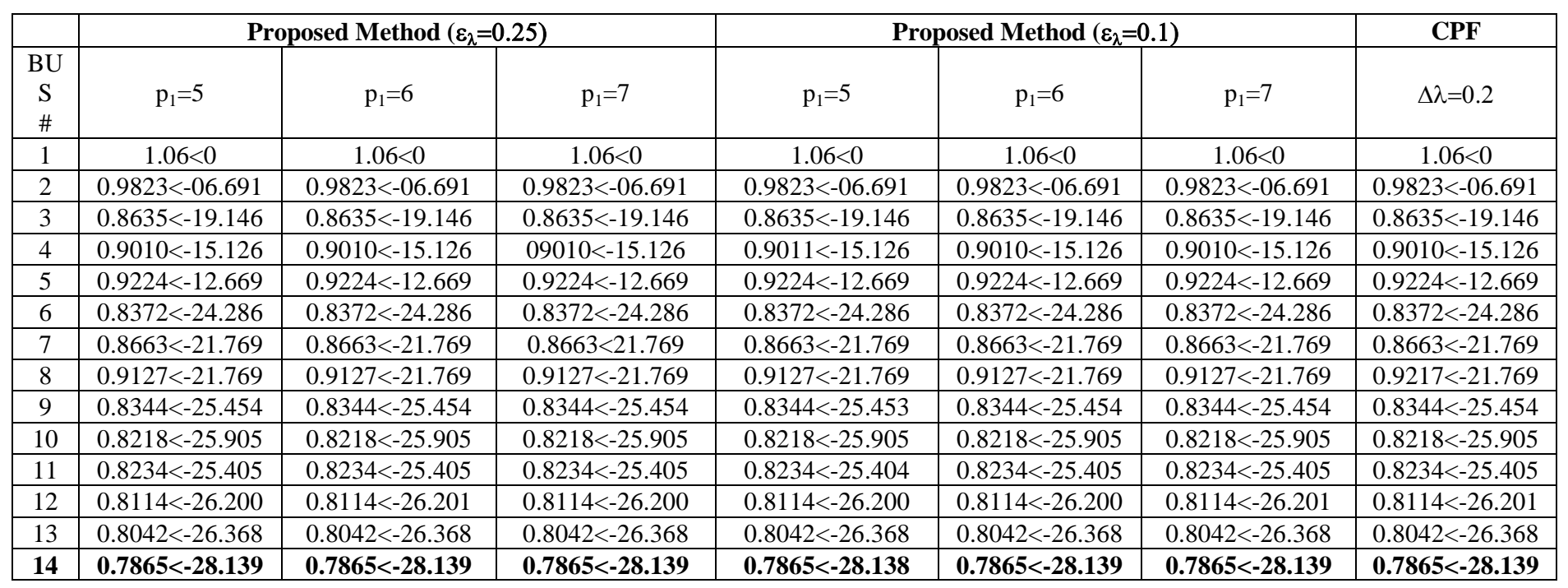

TABLE 2: A COMPARISON BETWEEN THE COMPUTATIONAL TIME BETWEEN THE PROPOSED METHOD AND THAT OF CPF METHOD

\begin{tabular}{|c|c|c|}
\hline Test System & Proposed Method & CPF \\
\hline IEEE 14-Bus & 0.11 Sec. & 0.31 Sec. \\
\hline IEEE 30-Bus & 0.27 Sec. & 0.78 Sec. \\
\hline IEEE 57-Bus & 0.93 Sec. & 2.18 Sec. \\
\hline Computer : DEL, INSPIRON 640m, Dual Core , 2*2 GB \\
\hline
\end{tabular}


TABLE 3: BUS VOLTAGES OF IEEE-14 BUS FOR DUE INCREASE IN LOAD AT SADDLE-SNB POINT RELATED TO THE BASE LOAD PATTERN

\begin{tabular}{|c|c|c|c|c|c|c|c|}
\hline \multirow[b]{2}{*}{$\begin{array}{c}\text { BUS } \\
\#\end{array}$} & \multirow[b]{2}{*}{ Base Case } & \multicolumn{2}{|c|}{$\begin{array}{c}\text { Proposed Method }\left(\varepsilon_{\mathrm{e} 14}=0.05\right) \\
\lambda_{\mathrm{cr}}=1.4997\end{array}$} & \multicolumn{2}{|c|}{$\begin{array}{c}\text { Proposed Method }\left(\varepsilon_{\mathrm{e} 14}=0.01\right) \\
\lambda_{\mathrm{cr}}=1.5141\end{array}$} & \multirow{2}{*}{$\begin{array}{c}\text { Proposed Method } \\
\qquad \begin{array}{c}* \lambda_{\mathrm{cr}}=1.5181 \\
\mathrm{p}_{2}=3\end{array}\end{array}$} & \multirow{2}{*}{$\begin{array}{c}\mathbf{C P F}^{* *} \\
\lambda_{\mathrm{cr}}=1.5187 \\
\Delta \lambda=0.1\end{array}$} \\
\hline & & $\mathrm{p}_{2}=3$ & $\mathrm{p}_{2}=5$ & $\mathrm{p}_{2}=3$ & $\mathrm{P}_{2}=5$ & & \\
\hline 1 & $1.06<0$ & $1.06<0$ & $1.06<0$ & $1.06<0$ & $1.06<0$ & $1.06<0$ & $1.06<0$ \\
\hline 2 & $\begin{array}{c}1.0389<- \\
04.910\end{array}$ & $\begin{array}{c}0.8906<- \\
07.876\end{array}$ & $\begin{array}{c}0.8906<- \\
07.876\end{array}$ & $0.8817<-07.950$ & $0.8817<-07.950$ & $0.8819<-07.960$ & $0.8816<-07.961$ \\
\hline 3 & $\begin{array}{c}0.9768<- \\
12.497 \\
\end{array}$ & $\begin{array}{c}0.6802<- \\
27.837 \\
\end{array}$ & $\begin{array}{c}0.6802<- \\
28.836 \\
\end{array}$ & $0.6616<-28.788$ & $0.6616<-28.788$ & $0.6619<-28.805$ & $0.6613<-28.835$ \\
\hline 4 & $\begin{array}{c}1.0041<- \\
10.297\end{array}$ & $\begin{array}{c}0.7250<- \\
20.383\end{array}$ & $\begin{array}{c}0.725<- \\
20.379\end{array}$ & $0.7081<-20.896$ & $0.7081<-20.896$ & $0.7086<-20.912$ & $0.7081<-20.927$ \\
\hline 5 & $\begin{array}{c}1.0145<- \\
08.783\end{array}$ & $\begin{array}{c}0.7641<- \\
16.400 \\
\end{array}$ & $\begin{array}{c}0.7641<- \\
16.400\end{array}$ & $0.7489<-16.732$ & $0.7489<-16.732$ & $0.7495<-16.750$ & $0.7490<-16.759$ \\
\hline 6 & $\begin{array}{c}0.9657<- \\
15.215\end{array}$ & $\begin{array}{c}0.5985<- \\
40.070\end{array}$ & $\begin{array}{c}0.5985<- \\
40.069\end{array}$ & $0.5780<-41.958$ & $0.5780<-41.958$ & $0.5793<-41.909$ & $0.5786<-41.971$ \\
\hline 7 & $\begin{array}{c}0.9934<- \\
14.061\end{array}$ & $\begin{array}{c}0.6344<- \\
33.497 \\
\end{array}$ & $\begin{array}{c}0.6344<- \\
33.497\end{array}$ & $0.6138<-34.846$ & $0.6138<-34.846$ & $0.6150<-34.834$ & $0.6144<-34.877$ \\
\hline 8 & $\begin{array}{c}1.0343<- \\
14.061\end{array}$ & $\begin{array}{c}0.6952<- \\
33.497 \\
\end{array}$ & $\begin{array}{c}0.6952<- \\
33.497 \\
\end{array}$ & $0.6763<-34.846$ & $0.6763<-34.846$ & $0.6774<-34.834$ & $0.6768<-34.877$ \\
\hline 9 & $\begin{array}{c}0.9756<- \\
16.054 \\
\end{array}$ & $\begin{array}{c}0.5732<- \\
41.990 \\
\end{array}$ & $\begin{array}{c}0.5732<- \\
41.989 \\
\end{array}$ & $0.5512<-44.015$ & $0.5512<-44.015$ & $0.5528<-43.966$ & $0.5520<-44.032$ \\
\hline 10 & $\begin{array}{c}0.9658<- \\
16.261 \\
\end{array}$ & $\begin{array}{c}0.5556<- \\
43.217 \\
\end{array}$ & $\begin{array}{c}0.5556<- \\
43.216 \\
\end{array}$ & $0.5328<-45.354$ & $0.5328<-45.354$ & $0.5344<-45.298$ & $0.5336<-45.368$ \\
\hline 11 & $\begin{array}{c}0.9621<- \\
15.914 \\
\end{array}$ & $\begin{array}{c}0.5667<- \\
42.310 \\
\end{array}$ & $\begin{array}{c}0.5667<- \\
42.313 \\
\end{array}$ & $0.5445<-44.375$ & $0.5445<-44.357$ & $0.5460<-44.319$ & $0.5453<-44.387$ \\
\hline 12 & $\begin{array}{c}0.9509<- \\
16.241\end{array}$ & $\begin{array}{c}0.5521<- \\
44.589\end{array}$ & $\begin{array}{c}0.5521<- \\
44.588\end{array}$ & $0.5304<-46.870$ & $0.5304<-46.870$ & $0.5319<-46.801$ & $0.5312<-46.876$ \\
\hline 13 & $\begin{array}{c}0.9474<- \\
16.357\end{array}$ & $\begin{array}{c}0.5378<- \\
44.952 \\
\end{array}$ & $\begin{array}{c}0.5378<- \\
44.951 \\
\end{array}$ & $0.5164<-47.335$ & $0.5164<-47.335$ & $0.5180<-47.268$ & $0.5173<-47.347$ \\
\hline $14^{* * * *}$ & $\begin{array}{c}0.9426<- \\
17.364\end{array}$ & $\begin{array}{c}0.4970<- \\
49.520\end{array}$ & $\begin{array}{c}0.4969<- \\
49.519\end{array}$ & $0.4815<-52.578$ & $0.4815<-52.578$ & $0.4839<-52.494$ & $0.4833<-52.594$ \\
\hline
\end{tabular}


TABLE 4: SNB POINT PROPERTY $\left(\lambda_{\mathrm{CR}}\right)$ IN IEEE-BUS STANDARDS

\begin{tabular}{|c|c|c|}
\hline IEEE Case Study & $\begin{array}{c}\lambda_{\text {cr }} \\
\text { (Proposed Method) }\end{array}$ & $\begin{array}{c}\lambda_{\text {cr }} \\
\text { (CPF Method) }\end{array}$ \\
\hline 14 BUS & 1.5181 & 1.5787 \\
\hline 30 BUS & 1.2879 & 1.2870 \\
\hline 57 BUS & 3.4836 & 3.4814 \\
\hline
\end{tabular}

TABLE 5: TEN POINTS OF LOWER PART OF V- $\lambda$ CURVE IN IEEE- 57 BUS SYSTEM $(*$ SNB POINT)

\begin{tabular}{|c|c|c|}
\hline Point & $\left|V_{31}\right|$ & $\begin{array}{c}\text { Load Parameter } \\
(\lambda)\end{array}$ \\
\hline $\mathbf{1}^{*}$ & $\begin{array}{c}\mathbf{0 . 4 5 8 9}<- \\
\mathbf{4 7 . 2 7 0}\end{array}$ & $\mathbf{3 . 4 8 1 4}$ \\
\hline 2 & 0.4356 & 3.2530 \\
\hline 3 & 0.4145 & 2.8344 \\
\hline 4 & 0.3963 & 2.6443 \\
\hline 5 & 0.3017 & 2.4542 \\
\hline 6 & 0.2564 & 1.8839 \\
\hline 7 & 0.1418 & 1.5037 \\
\hline 8 & 0.1011 & 0.9335 \\
\hline 9 & 0.0848 & 0.3632 \\
\hline 10 & 0.0768 & 0.0780 \\
\hline
\end{tabular}


TABLE 6: TEN POINTS OF LOWER PART OF V- $\lambda$ CURVE IN IEEE- 30 BUS SYSTEM $(*$ SNB POINT)

\begin{tabular}{|c|c|c|}
\hline Point & $\left|V_{30}\right|$ & Load Parameter $(\lambda)$ \\
\hline $\mathbf{1}^{*}$ & $\begin{array}{c}\mathbf{0 . 5 8 4 3}<- \\
\mathbf{4 2 . 8 0 7}\end{array}$ & $\mathbf{1 . 2 8 7 9}$ \\
\hline 2 & $0.5548<-45.291$ & 1.2710 \\
\hline 3 & $0.5324<-45.821$ & 1.2661 \\
\hline 4 & $0.5043<-47.458$ & 1.2442 \\
\hline 5 & $0.4638<-49.741$ & 1.1925 \\
\hline 6 & $0.4413<-52.112$ & 1.1525 \\
\hline 7 & $0.4166<-53.316$ & 1.0977 \\
\hline 8 & $0.3525<-54.532$ & 0.8993 \\
\hline 9 & $0.2369<-57.799$ & 0.3415 \\
\hline 10 & $0.2025<-58.190$ & 0.0915 \\
\hline
\end{tabular}

TABLE 7: TEN POINTS OF LOWER PART OF V- $\lambda$ CURVE IN IEEE- 14 BUS SYSTEM (* SNB POINT)

\begin{tabular}{|c|c|c|}
\hline Point & $\left|V_{14}\right|$ & Load Parameter $(\lambda)$ \\
\hline $\mathbf{1}^{*}$ & $\mathbf{0 . 4 2 9 0 < - 5 8 . 4 2 8}$ & $\mathbf{1 . 5 1 8 1}$ \\
\hline 2 & $0.4127<-60.697$ & 1.5160 \\
\hline 3 & $0.3716<-66.672$ & 1.4898 \\
\hline 4 & $0.3347<-71.972$ & 1.4375 \\
\hline 5 & $0.3195<74.01$ & 1.4092 \\
\hline 6 & $0.1638<-86430$ & 0.9688 \\
\hline 7 & $0.0937<-81.881$ & 0.5819 \\
\hline 8 & $0.0730<-77.640$ & 0.2529 \\
\hline 9 & $0.0701<-76.989$ & 0.1949 \\
\hline 10 & $0.0634<-75.320$ & 0.0401 \\
\hline
\end{tabular}


TABLE 8: ESTIMATION OF VSM FOR CONTINGENCY STATE USING THE PROPOSED METHOD

\begin{tabular}{|c|c|c|c|c|c|}
\hline Line Number & Bus2-Bus3 & Bus4-Bus5 & Bus6-Bus11 & Bus9-Bus10 & Bus12-Bus13 \\
\hline IEEE 14-BUS & 1.354 & 1.157 & 1.503 & 1.397 & 1.509 \\
\hline Line & Bus2-Bus5 & Bus4-Bus6 & Bus10-Bus21 & Bus12-Bus14 & Bus18-Bus19 \\
\hline IEEE 30-BUS & 0.408 & 0.993 & 1.249 & 1.168 & 1.056 \\
\hline Line 1 & us3-Bus4 & Bus6-Bus8 & Bus12-Bus16 & Bus19-Bus20 & Bus28-Bus29 \\
\hline IEEE 57-BUS & 1.558 & 1.547 & 2.850 & 1.574 & 0.508 \\
\hline
\end{tabular}

